\title{
Large-Scale Additive Manufacturing for Low Cost Small-Scale Wind Turbine Manufacturing
}

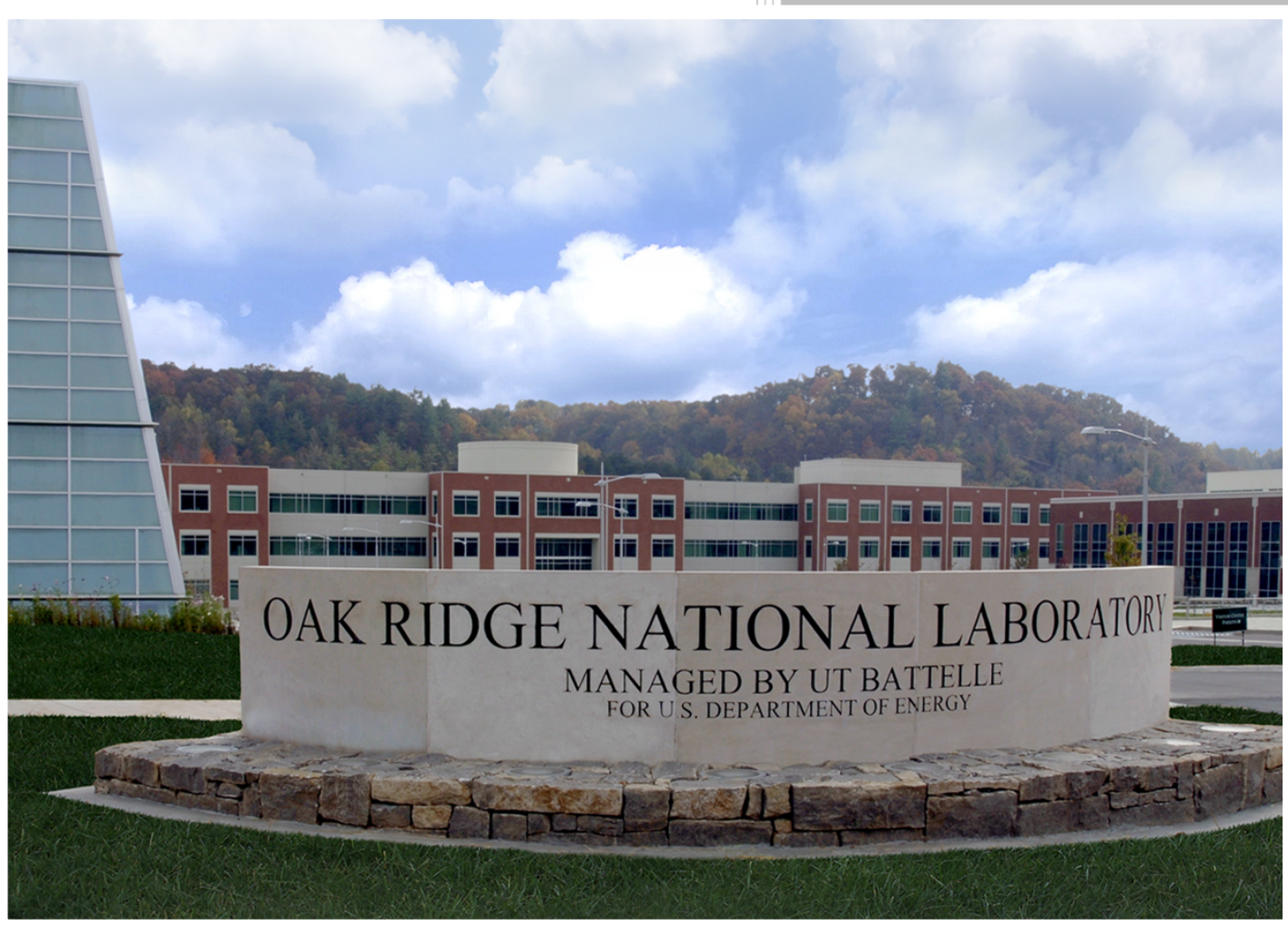

Brian Post

September 24, 2018 


\section{DOCUMENT AVAILABILITY}

Reports produced after January 1, 1996, are generally available free via US Department of Energy (DOE) SciTech Connect.

Website http://www.osti.gov/scitech/

Reports produced before January 1, 1996, may be purchased by members of the public from the following source:

National Technical Information Service

5285 Port Royal Road

Springfield, VA 22161

Telephone 703-605-6000 (1-800-553-6847)

TDD 703-487-4639

Fax 703-605-6900

E-mail info@ntis.gov

Website http://www.ntis.gov/help/ordermethods.aspx

Reports are available to DOE employees, DOE contractors, Energy Technology Data Exchange representatives, and International Nuclear Information System representatives from the following source:

Office of Scientific and Technical Information

PO Box 62

Oak Ridge, TN 37831

Telephone 865-576-8401

Fax 865-576-5728

E-mail reports@osti.gov

Website http://www.osti.gov/contact.html

This report was prepared as an account of work sponsored by an agency of the United States Government. Neither the United States Government nor any agency thereof, nor any of their employees, makes any warranty, express or implied, or assumes any legal liability or responsibility for the accuracy, completeness, or usefulness of any information, apparatus, product, or process disclosed, or represents that its use would not infringe privately owned rights. Reference herein to any specific commercial product, process, or service by trade name, trademark, manufacturer, or otherwise, does not necessarily constitute or imply its endorsement, recommendation, or favoring by the United States Government or any agency thereof. The views and opinions of authors expressed herein do not necessarily state or reflect those of the United States Government or any agency thereof. 
Energy and Transportation Sciences Division

Advanced Manufacturing Office

\section{Large-Scale Additive Manufacturing for Low Cost Small-Scale Wind Turbine Manufacturing}

Authors:

Brian Post

Phillip Chesser

Alex Roschli

Lonnie Love

Katherine Gaul

Date Published:

September 24, 2018

Prepared by

OAK RIDGE NATIONAL LABORATORY

Oak Ridge, Tennessee 37831-6283

managed by

UT-BATTELLE, LLC

for the

US DEPARTMENT OF ENERGY

under contract DE-AC05-00OR22725

Approved For Public Release 


\section{CONTENTS}

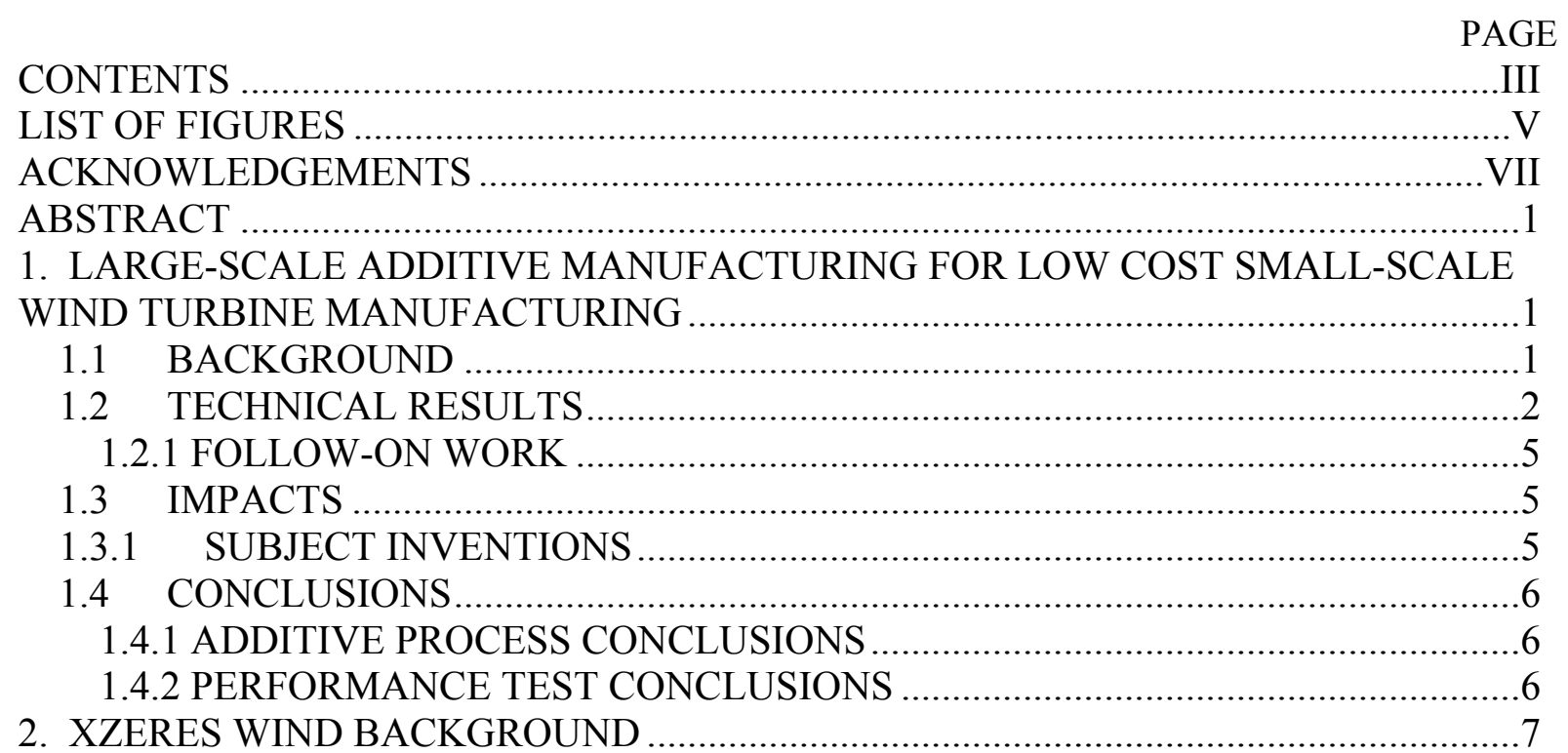




\section{LIST OF FIGURES}

Fig. 1. XZERES 442SR small wind turbine..............................................................

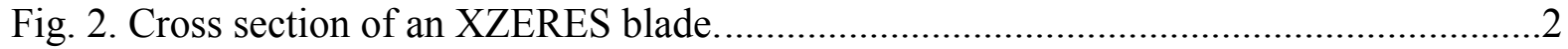

Fig. 3. Section of the CAD model of an XZERES blade with grooves left in the surface for pultruded rods.

Fig. 4. Prototype blade with two bead thick walls with a spar sitting in a groove (left) and a second prototype blade with a single bead wall and no spar (right) ....................................3

Fig. 5. Drawing of an XZERES blade illustrating flapwise, edgewise [or more technically

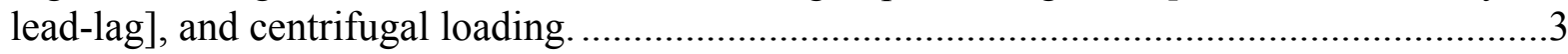

Fig. 6. Test set up using root bushings and bolts.......................................................

Fig. 7. Carbon fiber rods inserted and glued into the cut grooves of a prototype blade............4

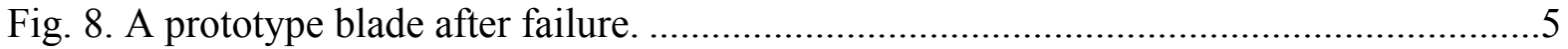




\section{ACKNOWLEDGEMENTS}

This CRADA NFE-18-07065 was conducted as a Technical Collaboration project within the Oak Ridge National Laboratory (ORNL) Manufacturing Demonstration Facility (MDF) sponsored by the US Department of Energy Advanced Manufacturing Office (CPS Agreement Number 24761).

Opportunities for MDF technical collaborations are listed in the announcement "Manufacturing Demonstration Facility Technology Collaborations for US Manufacturers in Advanced

Manufacturing and Materials Technologies" posted at http:/web.ornl.gov/sci/manufacturing/docs/FBO-ORNL-MDF-2013-2.pdf. The goal of technical collaborations is to engage industry partners to participate in short-term, collaborative projects within the Manufacturing Demonstration Facility (MDF) to assess applicability and of new energy efficient manufacturing technologies. Research sponsored by the U.S. Department of Energy, Office of Energy Efficiency and Renewable Energy, Advanced Manufacturing Office, under contract DE-AC0500OR22725 with UT-Battelle, LLC. 


\begin{abstract}
Oak Ridge National Laboratory's Manufacturing Demonstration Facility worked with XZERES Wind to fabricate small (in comparison to traditional wind energy systems) wind turbine blades using large-scale polymer additive manufacturing (AM). The results of this project showed promise for the use of AM in the production of small wind energy systems. Although, the large-scale polymer AM systems available for this project proved to be too large for this application, ORNL and XZERES Wind were able to prove that AM is a viable opportunity to improve small wind turbine blades.
\end{abstract}

\title{
1. LARGE-SCALE ADDITIVE MANUFACTURING FOR LOW COST SMALL-SCALE WIND TURBINE MANUFACTURING
}

This phase one technical collaboration project (MDF-TC-2018-136) began in April 25, 2018 and was completed on August 31, 2018. The collaborator, XZERES Wind, is a small business. This first phase proved that additive manufacturing (AM) offers advantages for the manufacture of small wind turbine blades.

\subsection{BACKGROUND}

XZERES Wind is a small-medium enterprise that specializes in the design, manufacture, and distribution of high quality distributed small wind turbines. This project has the potential to propel this company and its energy-saving technology into the global wind energy market.

The goal of this project is to explore the potential roles large-scale polymer and large-scale metal AM might have in reducing prototyping and production costs for small-scale ( 3 to 5 meter) wind blade manufacturing. The first phase focused on using polymer Big Area Additive Manufacturing (BAAM) to directly manufacture prototype blades. The goal was to demonstrate that the AM can be used, with prudent design, to manufacture prototype small wind turbine blades that can be used to rapidly evaluate wind blade performance.

XZERES Wind's current traditionally-manufactured wind turbine blades (Fig. 1 and Fig 2.) are manufactured from fiberglass with a foam core. Current 3-meter blades cost approximately $\$ 1.5 \mathrm{~K}$ and take many days to manufacture. Through AM, XZERES Wind and ORNL worked together to explore the substantial time and cost savings associated with this technology.
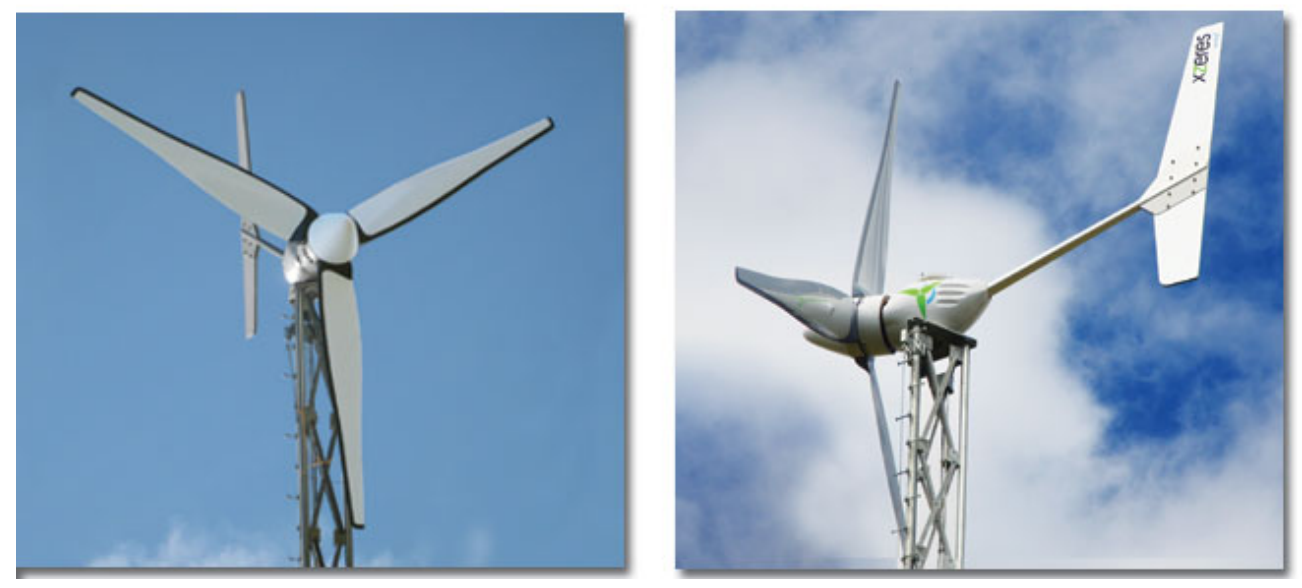

Fig. 1. XZERES 442SR small wind turbine. 


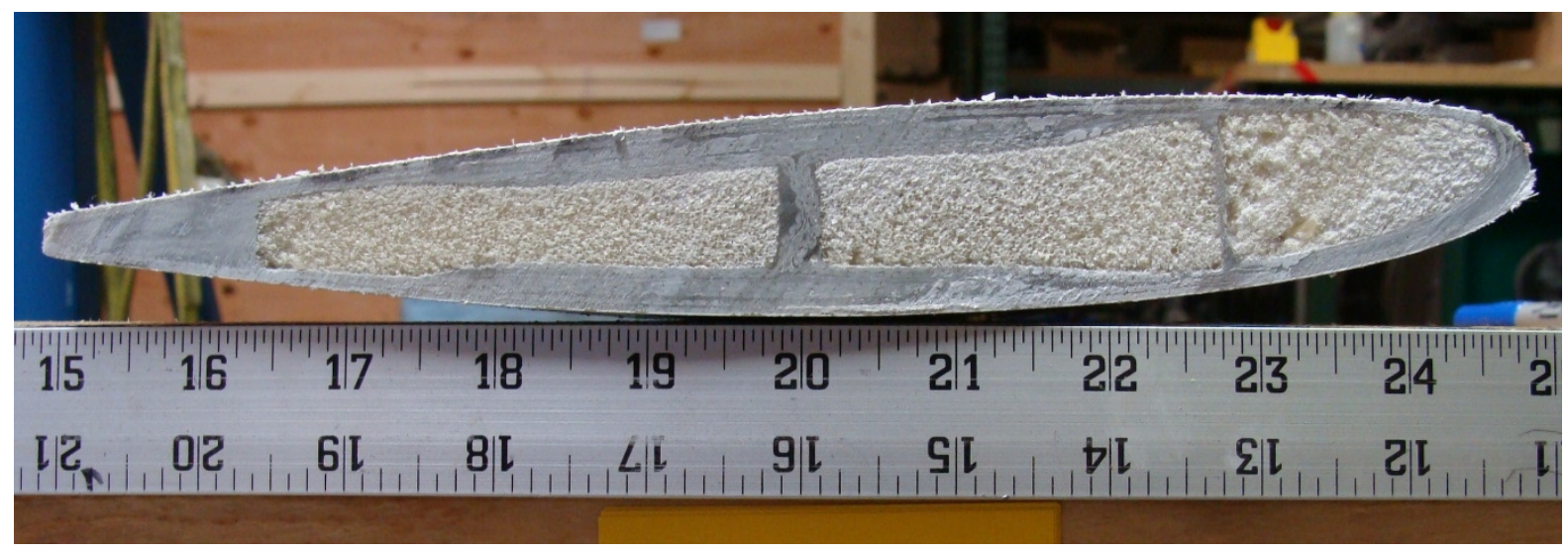

Fig. 2. Cross section of an XZERES blade.

\subsection{TECHNICAL RESULTS}

Phase one consisted of using polymer BAAM to rapidly manufacture small wind turbine blade sections ( 3 to 5 meters) for testing of form, fit, and function. This was achieved through a cooperative effort. XZERES began the effort by performing analysis on existing blade profiles and then designing a blade that was optimized for 3D printing. XZERES analysis of their current blades helped ORNL designers determine that 7 pultruded rods should be integrated into the design. Through iterations between ORNL researchers and XZERES staff, it was decided to test a 36" long section of the blade to prove the concept. The final design contained 7 grooves, left in the surface for the pultruded rods, each in the upper and lower surfaces respectively. These grooves were designed to allow for the insertion of pultruded carbon fiber rods (Fig. 3). The design had to consider that root bushings are required for the blade to be eventually mounted to a hub.

Originally, the design aimed to insert carbon fiber rods into subsurface holes within the blade. However, the BAAM system could not print on a small enough scale to create subsurface holes, so the holes were redesigned as surface grooves. Carbon fiber rods were then fixed within the grooves with adhesive.

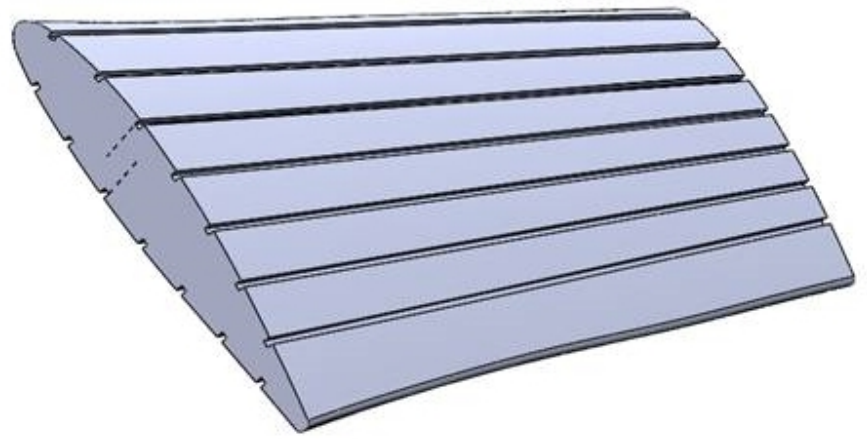

Fig. 3. Section of the CAD model of an XZERES blade with grooves left in the surface for pultruded rods.

The rods were inexpensive ( $\$ 40$ for 14 rods that were 3/16" in diameter and 6 rods that were $1 / 4$ " in diameter; all rods, regardless of diameter, measured 36" long), readily available from Strongwell, and flexible enough to allow for some level of bending to fit the tapering and curvature of the blade surface. 
Several iterations of prototype blades were printed. Two of the final sections are shown in Fig. 4. The two-bead walled prototype blade weighed $18.1 \mathrm{lb}$. (left), while the single-bead walled prototype weighed $10.8 \mathrm{lb}$. (right). The target mass for this section would have been approximately $12 \mathrm{lbs}$.

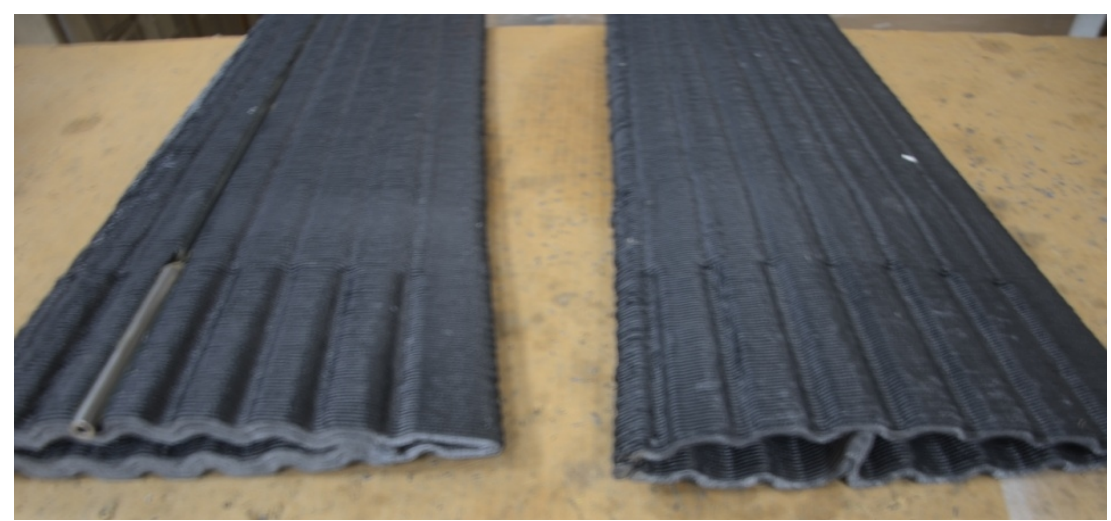

Fig. 4. Prototype blade with two bead thick walls with a spar sitting in a groove (left) and a second prototype blade with a single bead wall and no spar (right).

The prototype blades were printed using $20 \%$ carbon fiber reinforced acrylonitrile butadiene styrene (CF ABS) polymer. It took approximately 9 hours and 45 minutes to print two two-bead walled blade sections and two single-bead walled blade sections. The blades were printed with a 0.1 " nozzle, through a gantry-driven, extrusion-based additive manufacturing process.

A single flapwise (Fig. 5 left) load test was performed on a 3D printed blade section. The test determined the structural integrity of the 3D printed CF ABS blade section of the existing XZERES 442SR wind turbine blade.
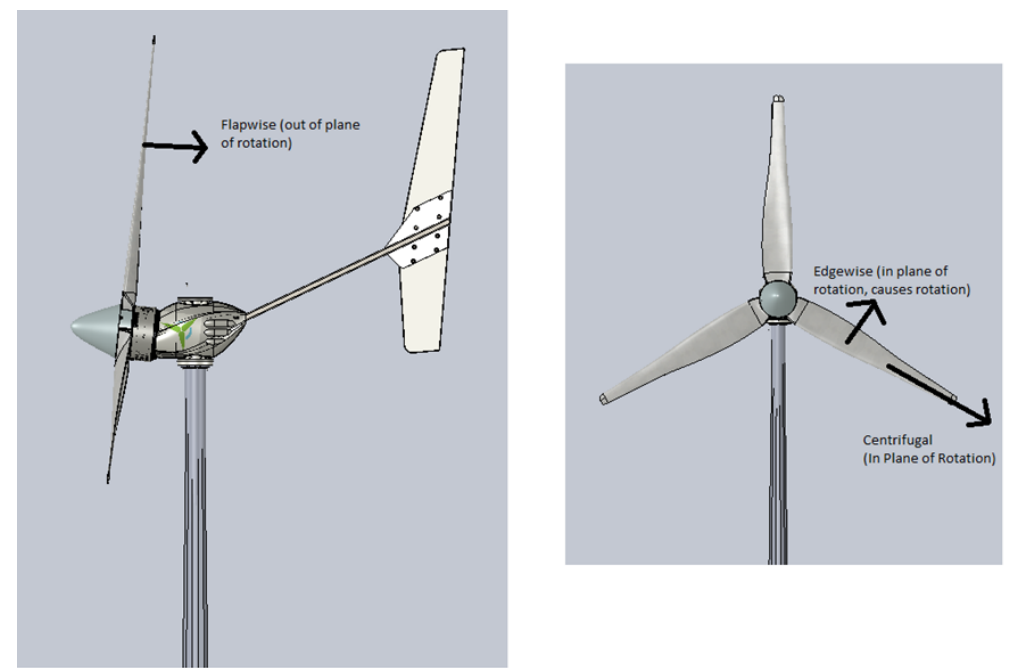

Fig. 5. Drawing of an XZERES blade illustrating flapwise, edgewise [or more technically lead-lag], and centrifugal loading.

The test set up consisted of mounting the prototype blade using root bushings (Fig. 6). The root section was designed using root bushings and flat plates. Each root bushing was designed to take 
a bolt on one end and provide length for adhesion between the carbon fiber rod and the root bushing on the other end. Each bolt tied directly to a base plate that was strapped to the alternator face to provide a direct load path to the alternator through two bolted joints.

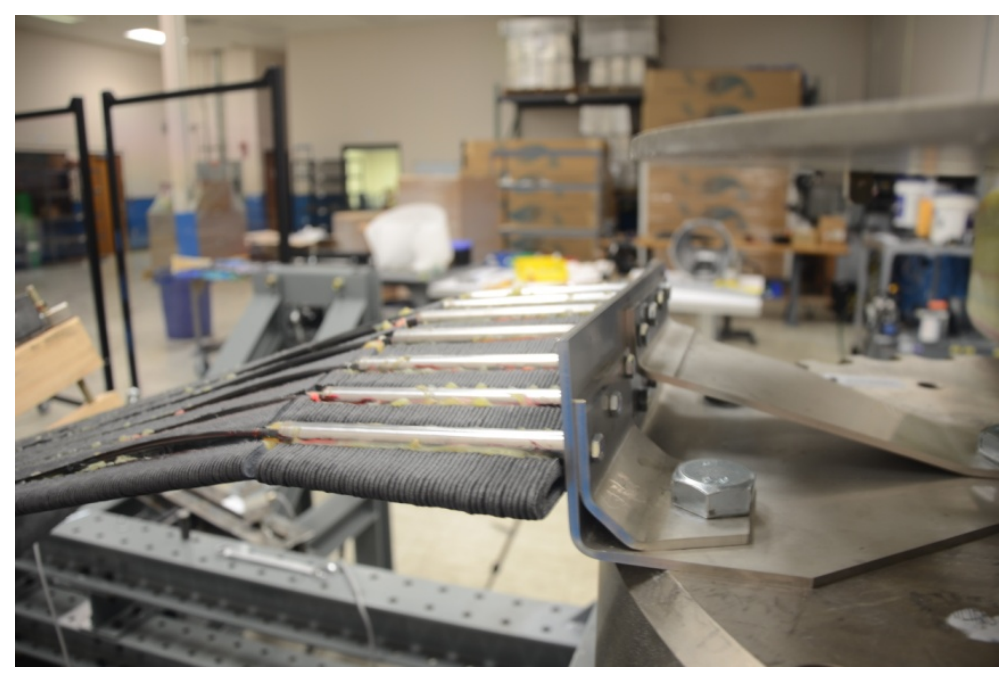

Fig. 6. Test set up using root bushings and bolts.

The grooves in the as-printed prototype blades did not provide sufficient depth for laying in and adhering the carbon fiber rods and root bushings. Therefore, post-processing of the grooves using a CNC machining process was necessary. XZERES used a DeWalt DW616 1.75HP fixed base router to cut the grooves. The grooves ended up being cut too large for the carbon fiber rods, which meant more acrylic adhesive was necessary to attach the rods in the grooves. (Fig. 7)

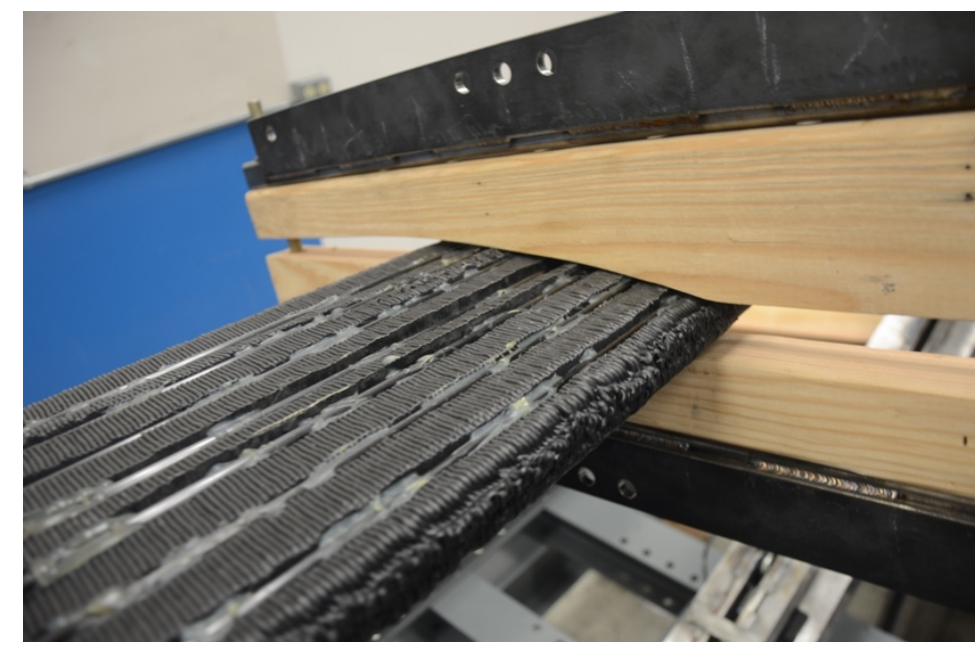

Fig. 7. Carbon fiber rods inserted and glued into the cut grooves of a prototype blade.

An Omega LC101-2.5k Load Cell read by a HP34970A DAS that was powered by a BK precision DC power supply was used to measure the forces applied by the test. A load frame built by XZERES was used to apply the force. The force measurements were recorded within $\pm 3 \mathrm{lbf}$. To create a blade root bending moment properly representing the ultimate load case (IEC 61400-2 Load Case H: Parked Wind Loading), a load minimum of 248.6lbs was applied at 34in from the section root. In actuality, the blade withstood $615 \mathrm{lbs}$ applied at 34in from the root before failure occurred 
(Figure 8). This correlates to 3.4 times the max ultimate load as determined in the standards (IEC $61400-2$, using simplified loads approach), well over the $1.4 \mathrm{x}$ target. The failure mode was primarily in the root bushings, where the 2in of overlap and bonding between the sleeve's inner diameter and the carbon fiber rod failed, causing the carbon fiber rods to slide out approximately $1 \mathrm{~cm}$ from their original locations. The primary failure in the root bushing allowed significant deflection in the blade section and led to two secondary failures. The accompanying failures were adhesive debonding between the AM blade and the reinforcing poles at the blade root and layer-to-layer separation of the $\mathrm{CF}$ ABS at the first section after the blade root bushings.

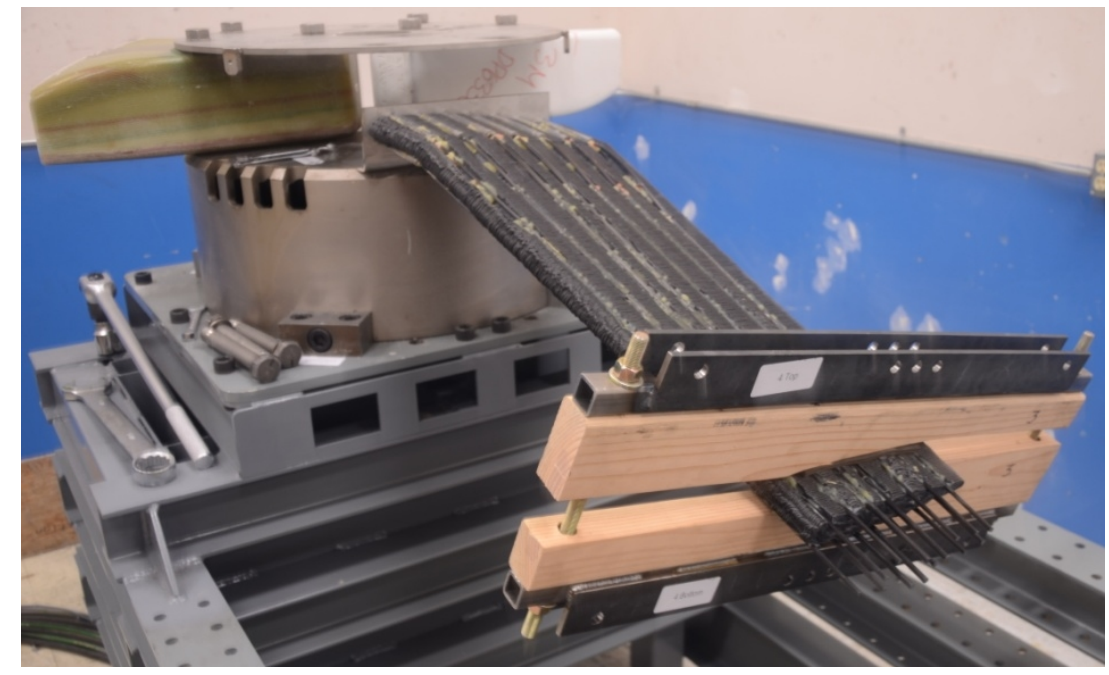

Fig. 8. A prototype blade after failure.

\subsubsection{Follow-On Work}

The second phase of this work will explore other BAAM techniques with the goal of taking advantage of AM in other areas of the blade manufacturing process. Targets include reducing material usage, decreasing cycling time, and decreasing necessary labor. Reducing the manufacturing cost of wind turbines will reduce the overall cost, which will expand the areas where small scale wind turbines are economically viable.

\subsection{IMPACTS}

There are several potential impacts of this project as it relates to the use of AM technology by XZERES regarding the manufacture of wind turbine blades. First, there is anticipated reduction in the amount of time consumed on development and prototyping of new blade designs. Currently, a time savings of 4.5 months (from six months to six weeks) is believed to be attainable. This time savings will also enable validation to occur more rapidly. The overall impact of this phase one effort is the realization that direct printing of wind turbine blades is not practical with current equipment, even for prototyping.

\subsubsection{SUBJECT INVENTIONS}

There are no subject inventions associated with this CRADA . 


\subsection{CONCLUSIONS}

\subsubsection{Additive Process Conclusions}

The additive process opens doors to quicker prototyping with less cost. However, the scale of the polymer BAAM system used in this project was nearly too large for this application. The prototype blades require a high enough print resolution to create precise grooves, corners, and tapering at the tips. A medium-scale polymer system could be an appropriate solution. A medium-scale system will have improved print resolution without sacrificing all of the time savings associated with scaling up $3 \mathrm{D}$ printing.

\subsubsection{Performance Test Conclusions}

The load test was deemed successful in that the load-carrying capacity of the tested section was more than sufficient. The blade withstood $615 \mathrm{lbs}$ applied at 34 in from the root before failure occurred. This is a performance to 3.4 times the rated peak load. Though the section failed at the first layer outside of the root bushings, the bushings themselves and the straps holding the section remained sufficient. The section remained rigid until failure, so it is difficult to say which material was carrying most of the load to that point. At the root, the carbon fiber rods pulled out of the root bushings and then subsequently out of their grooves. This could likely be prevented with more overlap between root bushings and rods, increased surface roughness on the two mating surfaces, and possibly a different adhesive. 


\section{XZERES WIND BACKGROUND}

In early 2010, XZERES CORPORATION acquired the assets of Abundant Renewable Energy, LLC. XZERES Wind's product portfolio includes $2.4 \mathrm{~kW}$ wind turbine and $10 \mathrm{~kW}$ rated power systems, with additional larger systems in development. Each system is comprised of a wind turbine, power electronics, towers, and auxiliary components providing a complete solution.

XZERES Wind's high efficiency design has fewer moving parts providing reduced service \& maintenance cost, easy installation across a wide variety of conditions, and capturing maximum benefits in low wind speed environments. Additionally, these products have numerous systems deployed in North America, a10-year manufacturer's warranty, and a durable wind turbine system exceeding 20 year life.

XZERES Wind designs, manufactures, and distributes high quality distributed small wind turbines $(2.4 \mathrm{~kW}-10 \mathrm{~kW}$ systems). XZERES Wind offers connected and off grid wind turbine systems that are used for electrical power generation for applications such as residential, micro-grid based rural electrification, agricultural, small business, rural electric utility systems, government, and other corporate infrastructure applications. XZERES' wind turbine systems are focused on distributed energy, where a specific machine's energy output is largely or entirely used on-site where the equipment is installed, as well as grid connected applications. 